\title{
RITUALIDAD FÚNEBRE E IDENTIDAD EN EL QUERO Y EL TAZÓN TUMILACA DE MOQUEGUA, PERÚ
}

\author{
FUNERARY RITUALITY AND IDENTITY IN THE TUMILACA QUERO \\ AND BOWL FROM MOQUEGUA, PERU
}

Juan Pablo Ogalde \& Nicola Sharratt $^{B}$

Se caracterizan queros y tazones del sitio Tumilaca la Chimba, Moquegua, Perú. En su elaboración se empleó el sistema de anillos superpuestos para ganar altura, además de alisado, pulido, engobe y decoración de superficie. Los tazones aparecen en contextos fúnebres con marcas de uso previo, no así los queros, que parecieran ser hechos ex profeso y apresuradamente para el rito fúnebre. Así, los estilos cerámicos posteriores a los procesos estatales del Horizonte Medio (5001000 DC) derivados de la tradición alfarera Tiwanaku, deben su desarrollo tecnológico a decisiones culturales selectivas del grupo, motivadas posiblemente por escenarios sociales cotidianos, íntimos y ancestrales.

Palabras clave: quero, Tiwanaku, valle del Osmore, iconografía, cerámica.

This paper describes queros and bowls from the site of Tumilaca la Chimba, Moquegua, Peru. Their elaboration used the system of superimposed rings to gain height, with smoothing, polishing, slipping and surface decoration. The bowls included in funerary contexts show evidence of having been used previously, which is not the case for the queros, which appear to have been produced intentionally and hastily for the funerary rite. We propose that the ceramic styles that post-date the Middle Horizon state processes (500-1000 AD) and derived from Tiwanaku ceramic traditions, owe their technological development to the selective choices of the group, which could have been motivated by social, private, and ancestral settings.

Keywords: queros, Tiwanaku, Osmore valley, iconography, ceramic.

\section{INTRODUCCIÓN}

Se presenta una discusión preliminar acerca del tazón y del vaso denominado quero, ambos artefactos cerámicos del estilo Tumilaca, tradición alfarera del Horizonte Medio Terminal (950-1250 DC) definida a partir del sitio arqueológico Tumilaca la Chimba, Moquegua, Perú (fig. 1). La alfarería Tumilaca se reconoce como una tradición cerámica derivada del Horizonte Medio (500-1100 DC), heredera de valores tecnológicos y decorativos que fueron parte de los desarrollos alfareros del estilo Tiwanaku, Estado altiplánico vigente durante dicho período. Así, hay elementos de continuidad en la cerámica que son claramente reconocibles respecto del estilo Tiwanaku (formas, elementos iconográficos, etc.), lo cual es coherente con la calidad de poblaciones post-Tiwanaku de estos grupos (Owen \& Goldstein 2001; Goldstein 2005; Owen 2005; Sharratt 2015, 2016a). Sin embargo, se esperarían también rasgos culturales rupturistas relacionados con la nueva situación posestatal de estos grupos, lo que, ciertamente, podría expresarse materialmente como cambios tecnológicos factuales o simbólicos en estos artefactos. En el presente estudio exploratorio del quero y del tazón Tumilaca se indaga

A Juan Pablo Ogalde, Instituto de Alta Investigación, Universidad de Tarapacá, Arica, Chile. ORCiD: 0000-0002-0760-4751. E-mail: jpabloogalde@yahoo.es

B Nicola Sharratt, Departamento de Antropología, Georgia State University, Atlanta, EE.UU. ORCID: 0000-0001-9864-0169. E-mail: nsharratt@gsu.edu

Recibido: septiembre 2019. Aprobado: noviembre 2020. 


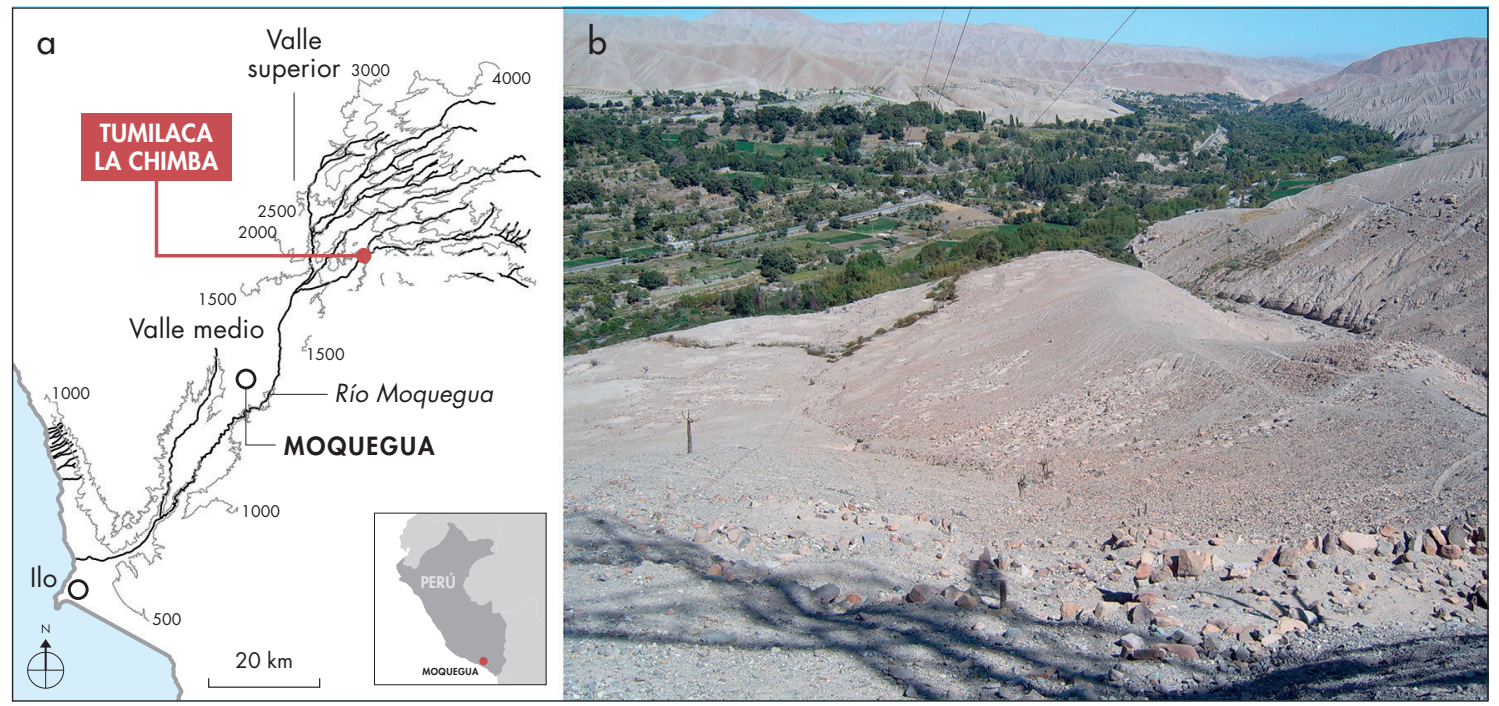

Figura 1. Sitio Tumilaca la Chimba, Moquegua, Perú: a) ubicación geográfica; b) vista del sitio, con los cementerios en primer plano. Figure 1. Tumilaca la Chimba site, Moquegua, Peru: a) geographical location; $\boldsymbol{b}$ ) view of the site, with the cemeteries in the foreground.

sobre posibles elementos de continuidad y ruptura cultural en los ítems de manufactura, decoración y uso de estos artefactos enterrados con las poblaciones arqueológicas de Tumilaca la Chimba.

\section{La cerámica Tumilaca y el estilo Tiwanaku}

El sitio Tumilaca la Chimba está ubicado a $1900 \mathrm{msnm}$, arriba del río Tumilaca en el valle superior de Moquegua (fig. 1a) (Bermann et al. 1989; Bawden 1989, 1993). Presenta dos ocupaciones consecutivas: la primera está asociada al estilo cerámico denominado Tumilaca (950-1250 DC), y la segunda, al estilo Estuquiña, que es la manifestación local del Período Intermedio Tardío (Bawden 1989, 1993). La ocupación Tumilaca incluye una aldea y cuatro cementerios localizados en las faldas del cerro La Chimba (fig. 1b). Diversas investigaciones se han llevado a cabo en el sitio, con excavaciones en los contextos residenciales y ceremoniales de la aldea, así como en los cuatro cementerios, estudiando, entre otros temas, la organización sociopolítica de estas poblaciones, sus prácticas cotidianas y rituales, la alfarería y producción de bienes, la participación en redes de economía, las patologías y los índices de salud, las relaciones con la colonia original de inmigrantes del altiplano, el impacto del colapso político del Estado Tiwanaku y la construcción de identidad en dicha si- tuación (Sharratt 2010, 2011, 2015, 2016a, 2016b, 2017, 2019, 2020; Sutter \& Sharratt 2010; Sharratt et al. 2012; Sharratt et al. 2015; Parker \& Sharratt 2017; Lowman et al. 2019). El conjunto de esta evidencia ha permitido establecer que la ocupación Tumilaca se conforma con grupos humanos que estaban migrando valle arriba a partir de la desintegración de la colonia altiplánica que se había instalado en el valle medio de Moquegua, bajo el alero del Estado Tiwanaku. Estos eventos y sus procesos sociales, que podrían haber comenzado ca. 950 DC, coinciden o se derivan del fin del Horizonte Medio y son centrales para entender parte del colapso de Tiwanaku y la consecuente interpretación cultural de los períodos posteriores relativos a las poblaciones posestatales (Goldstein \& Owen 2001; Owen \& Goldstein 2001; Owen 2005).

El arduo y amplio trabajo empírico hecho hasta ahora para comprender el desarrollo del Estado Tiwanaku y sus consecuencias culturales de largo plazo permite plantear que, en la conformación social del Estado altiplánico y sus colonias, los estilos cerámicos jugaron un rol protagónico. Precisamente, el conjunto cerámico del denominado estilo Tiwanaku ha sido fundamental para determinar las secuencias cronológicas y las fases culturales del Estado altiplánico (Bennett 1936; Rydén 1947; Wallace 1957; Ponce Sanginés 1981; Bermann 1990; Albarracín-Jordán \& Mathews 1990; Mathews 1992; Cook 1994; Alconini 1995; Albarracín-Jordán 1997; 
Janusek 2002, 2003); los primeros trabajos científicos definieron este estilo cerámico en sitios altiplánicos importantes que centralizaron fuerzas productivas, rituales y administrativas de grandes áreas. Esto homogeneizó diversos materiales alfareros de distinto origen geográfico y étnico, generando una conceptualización espacial y cronológica, unificada y lineal del estilo Tiwanaku (por ejemplo, Bennett 1934, 1936; Rydén 1947; Wallace 1957; Ponce Sanginés 1981). Por lo tanto, este supuesto estilo unificado ha sido considerado como paradigma para evaluar los desarrollos alfareros derivados del Horizonte Medio (i. e., el estilo Tumilaca), en el cual las poblaciones posestatales presentan progresos fragmentarios, conservando solo algunos aspectos del acervo cerámico total del estilo Tiwanaku (Uribe 1999; Goldstein \& Owen 2001; Owen \& Goldstein 2001; Goldstein 2005; Owen 2005; Sharratt 2015, 2016a). Esto se ha interpretado como un rechazo de las poblaciones posestatales a los valores corporativos impositivos del Tiwanaku o como un empobrecimiento tecnológico en ausencia de las redes del Estado. Estas ideas materialistas y centralistas son críticas, pues sugieren elementos de ruptura y subvaloración que afectan directamente las cadenas productivas de los objetos cerámicos en la medida en que el Estado Tiwanaku cesaba en su influencia, lo que desembocaría en el diseño factual y simbólico del artefacto.

Sin embargo, existe un elemento fundamental que conviene considerar ante este panorama, esto es, la supuesta uniformidad del estilo Tiwanaku durante el Horizonte Medio. Este planteamiento homogéneo inicial mostró rápidamente problemas y una mayor complejidad para este estudio. En algunas áreas coexistieron hasta tres "fases culturales". Si bien en otros lugares importantes los distintos estilos cerámicos aparecían selectivamente, en otras tradiciones alfareras menores se mantuvieron como unidades independientes en el tiempo en las áreas nucleares del Estado Tiwanaku (Alconini 1995; Burkholder 2001; Janusek 2002, 2003). La consideración de este problema en el área altiplánica, sumada a una mejor comprensión de las colonias tiwanakotas del área de Moquegua y las poblaciones post-Tiwanaku que generó su colapso, nos permite proponer que fueron varios los grupos sociales o étnicos que utilizaron la experticia cerámica para expresar parte de su identidad social durante el Horizonte Medio y los períodos cronológicos inmediatamente posteriores (Alconini 1995; Goldstein \& Owen 2001; Owen \& Goldstein 2001; Janusek 2002, 2003; Goldstein 2005; Korpisaari \& Chacama 2015;
Sharratt 2015). Es decir, en Tiwanaku no hubo un estilo cerámico corporativo único ni estandarizado, sino más bien una diversidad interna de estilos alfareros acorde con las múltiples identidades que se negociaron en su momento, algunas de las cuales permanecen como tradiciones alfareras durante centurias.

Este hecho es relevante respecto del problema de los grupos humanos derivados de la desintegración de las colonias tiwanakotas, pues la multiculturalidad de identidades diversas existentes en las colonias del Estado altiplánico fue el fermento desde el cual emergieron posteriormente las distintas poblaciones posestatales. Así, respecto del ámbito de interpretación centralista y materialista del estilo Tiwanaku que supone una decadencia de las tradiciones alfareras post-Tiwanaku, existe otro tipo de escenario configurativo, en el cual las decisiones culturales íntimas del grupo posestatal desembocarían fenomenológicamente en un estilo cerámico que les será distintivo (Goldstein 2005; Sharratt 2016a), afectando y adaptando desde allí las cadenas materiales de producción. Este último acercamiento es el que se quiere aplicar exploratoriamente al estudio del quero y tazón Tumilaca, en el que la manufactura, la decoración y el uso de estos artefactos serán los elementos que permitirán evaluar la continuidad y la ruptura cultural que significan dichos artefactos respecto del Horizonte Medio. Se intenta enfatizar aquellos aspectos discursivos que sugieren un cambio cultural basado en las decisiones del grupo respecto de su condición posestatal.

\section{MATERIALES}

Las cerámicas analizadas de Tumilaca la Chimba corresponden a un total de 14 piezas provenientes de tres cementerios (unidades 45,46 y 47 ), de un contexto doméstico (unidad 52) y de un contexto ceremonial (unidad 54). Así, se ha querido incorporar queros y tazones de distintos contextos arqueológicos para enriquecer la discusión. Esta muestra alfarera se compone de cinco queros y seis tazones en muy buen estado de conservación, una jarra en iguales condiciones y dos fragmentos de sahumadores (tabla 1).

La mayor parte del material analizado proviene de tres de los cinco cementerios excavados en Tumilaca la Chimba, uno de los cuales está asociado al Período Intermedio Tardío. Al respecto, el patrón funerario de la ocupación Tumilaca es semejante al de la fase 
Tabla 1. Código de las piezas (Museo Contisuyu) y descripción de la forma. Table 1. Code of the pieces (Contisuyu Museum) and description of the shape.

\begin{tabular}{|c|c|c|}
\hline n. ${ }^{\circ}$ & \multicolumn{2}{|c|}{ UNIDAD 45 CEMENTERIO } \\
\hline 1 & CB07-45-0006 & Quero \\
\hline \multirow[t]{2}{*}{2} & CB07-45-0015 & Tazón \\
\hline & \multicolumn{2}{|c|}{ UNIDAD 46 CEMENTERIO } \\
\hline 3 & СВ07-46-0012 & Fragmento sahumador \\
\hline 4 & CB07-46-0013 & Fragmento sahumador \\
\hline 5 & СB07-46-0014 & Tazón \\
\hline 6 & CB07-46-0015 & Jarra \\
\hline 7 & СВ07-46-0016 & Tazón \\
\hline 8 & CB07-46-0018 & Quero \\
\hline \multirow[t]{2}{*}{9} & СВ07-46-0019 & Tazón \\
\hline & \multicolumn{2}{|c|}{ UNIDAD 47 CEMENTERIO } \\
\hline 10 & CB06-47-0025 & Quero \\
\hline 11 & СB06-47-0026 & Quero \\
\hline \multirow[t]{2}{*}{12} & СB06-47-0027 & Tazón \\
\hline & \multicolumn{2}{|c|}{ UNIDAD 52 CONTEXTO DOMÉSTICO } \\
\hline \multirow[t]{2}{*}{13} & CB12-52-0103 & Tazón \\
\hline & \multicolumn{2}{|c|}{ UNIDAD 54 CONTEXTO RITUAL } \\
\hline 14 & CB12-54-0381 & Quero \\
\hline
\end{tabular}

Chen Chen y consiste en entierros individuales y primarios, puestos en cistas u hoyos subterráneos, donde los cuerpos son enrollados en uno o dos textiles y ubicados en una posición flexionada y sentada mirando hacia el este. Pueden ser acompañados por vasijas cerámicas correspondientes a queros, tazones, y jarras (fig. 2a), cucharas y cajitas de madera, cuentas de crisocola, calabazas, ajugas y otros elementos (Sharratt 2010, 2011, 2015).

La figura 2a muestra un ejemplo de las piezas funerarias. Se trata de uno de los queros analizados (CB06-47-0025) hallado en el cementerio Tumilaca, unidad 47. Por otro lado, la unidad 54 (fig. 2b) consiste en una estructura que consta de un muro perimetral bajo, de veinte por seis metros, con excavaciones en un área interna de siete por seis metros que muestran evidencias de actividades de quemado y restos de varias vasijas rotas. Dichas prácticas fueron ejecutadas cerca de varios hoyos poco profundos y limpios, los cuales
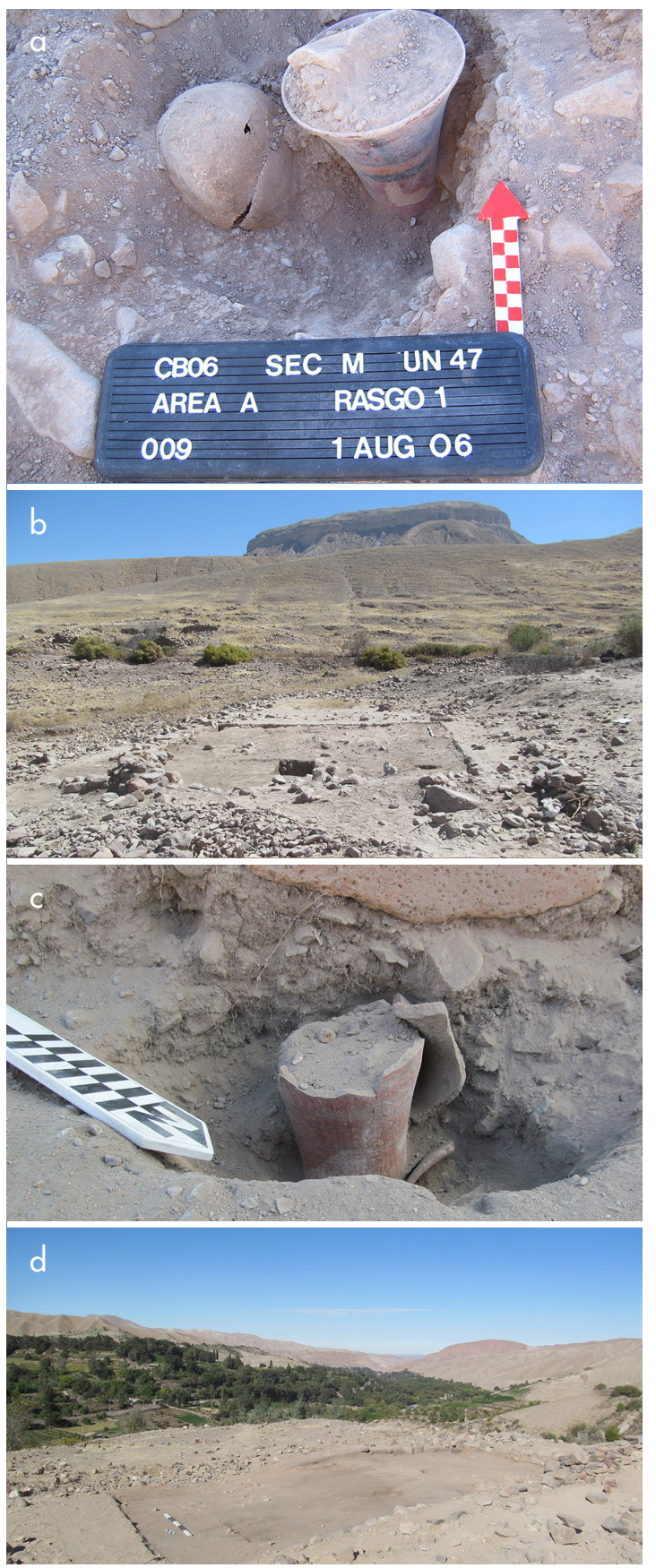

Figura 2. Los distintos contextos arqueológicos estudiados: a) quero (CB06-47-0025) hallado en el cementerio Tumilaca, denominado unidad 47 ; b) sitio ritual rústico denominado unidad 54; c) quero (CB12-54-0381) encontrado en la unidad 54; d) emplazamiento del sitio habitacional Tumilaca en la unidad 52. Figure 2. The different archaeological contexts studied: a) quero (CB06-47-0025) found in Tumilaca cemetery, called unit 47; b) rustic ritual site, called unit 54; c) quero (CB12-54-0381) found in unit 54; d) location of the Tumilaca housing site in unit 52. 


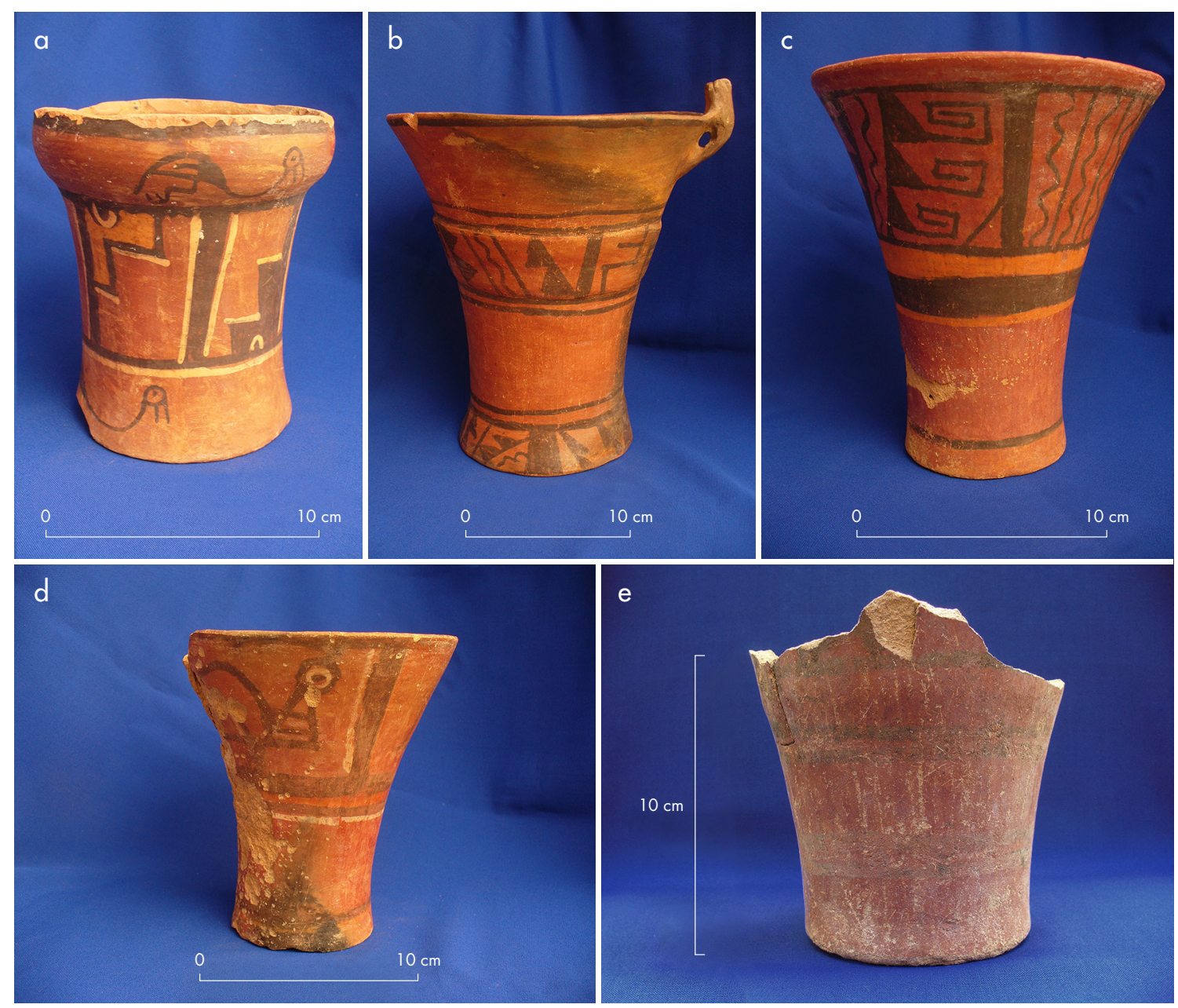

Figura 3. Queros: a) quero analizado hallado en el cementerio C45 (CB07-45-0006; b) quero hallado en el cementerio C46 (CB07-460018); c y e) queros provenientes del cementerio C47 (CB06-47-0025 y CB06-47-0026, respectivamente); d) quero hallado en contextos ceremoniales (CB12-54-0381). Figure 3. Queros: a) analyzed quero found in cemetery C45 (CB07-45-0006); b) quero found in cemetery C46 (CB07-46-0018); $c$ and $e$ ) queros from cemetery C47 (CB06-47-0025 and CB06-47-0026, respectively); $d$ ) quero found in ceremonial contexts (CB12-54-0381).

tenían dimensiones similares. Debido a las actividades realizadas en la estructura $-\mathrm{y}$ sus similitudes respecto de los rituales celebrados en contextos ceremoniales de sitios Tiwanaku- y a la ausencia de evidencia de labores domésticas, se interpretó la unidad 54 como un espacio ceremonial de carácter muy rústico (Sharratt 2016a). Durante las excavaciones, ahí se encontraron un quero que ha sido analizado (CB12-54-0381, fig. 2c) $\mathrm{y}$ un incensario zoomórfico, ambos enterrados bajo la superficie de la estructura. Finalmente, la unidad 52 se considera una estructura doméstica localizada en una fila de casas del estilo Tumilaca (fig. 2b). En comparación con otras casas excavadas en Tumilaca la Chimba, esta unidad muestra una construcción de menor calidad, compuesta de un solo espacio interior asociado con un patio exterior, en comparación con otras casas que cuentan con dos recintos internos y un patio exterior. En este último tipo de contexto arqueológico fue hallado el tazón analizado (CB12-52-0103), el cual fue enterrado boca abajo en el subsuelo del espacio interno de la casa, asociado a dos bolas de piedra. Dicho tazón representaría un artefacto alfarero del ámbito doméstico.

Cinco queros son las piezas estudiadas relativas a la tradición queriforme Tumilaca (fig. 3). Cuatro provienen de contextos fúnebres (cementerios C45, C46 y C47) y uno fue hallado en contextos ceremoniales. 

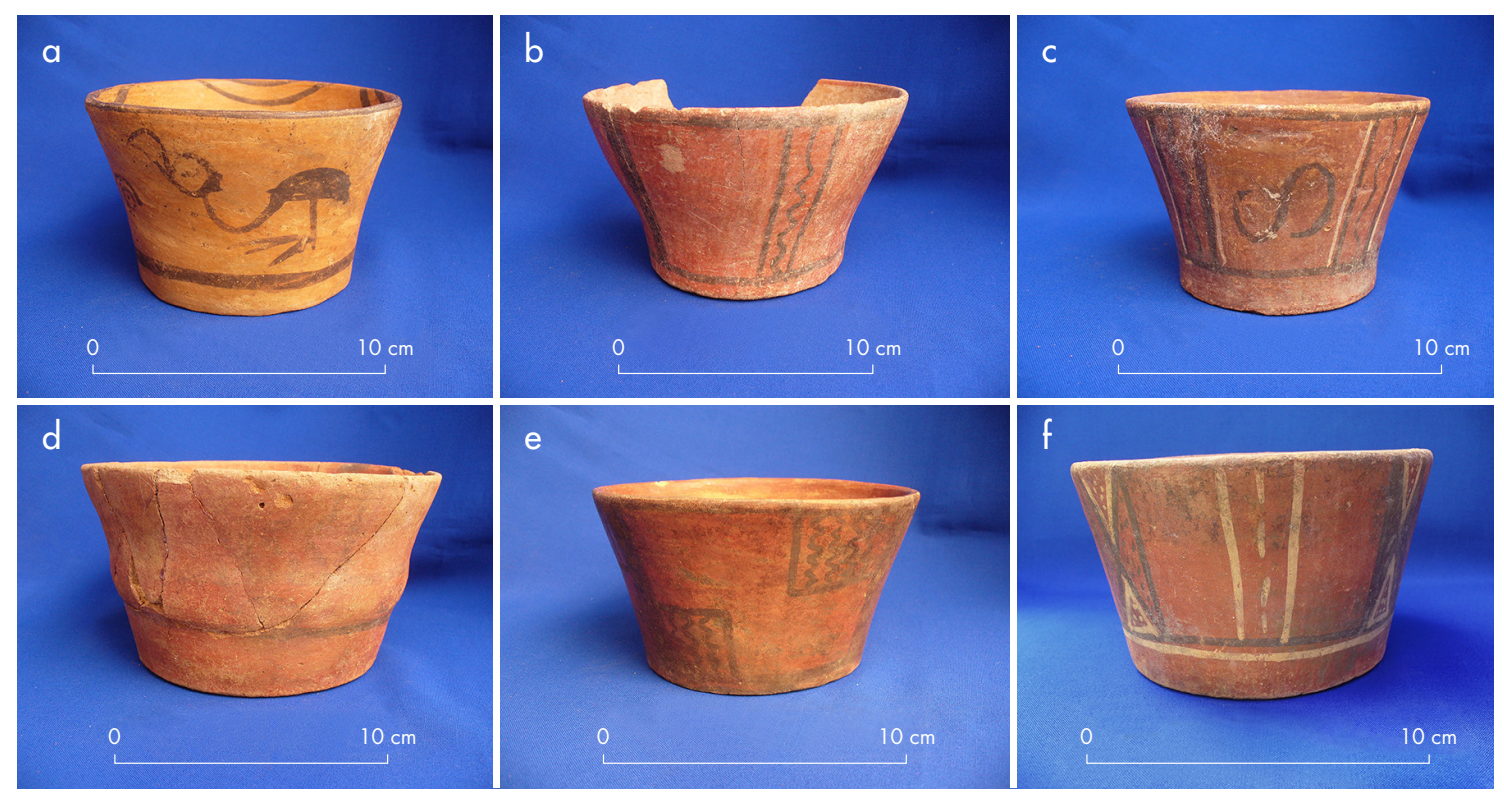

Figura 4. Tazones: a) tazón analizado proveniente del cementerio C45 (CB07-45-00015); b, c y d) tazones provenientes del cementerio C46 (CB07-46-0014, CB07-46-0016 y CB07-46-0019, respectivamente); e) tazón del cementerio C47 (CB06-47-0027); f) tazón hallado en contexto doméstico (CB12-52-0103). Figure 4. Bowls: a) cup analyzed from cemetery C45 (CB07-45-00015); $b, c$ and d) bowls from cemetery C46 (CB07-46-0014, CB07-46-0016 and CB07-46-0019, respectively); e) bowl from cemetery C47 (CB06-47-0027); f) bowl found in domestic context (CB12-52-0103).
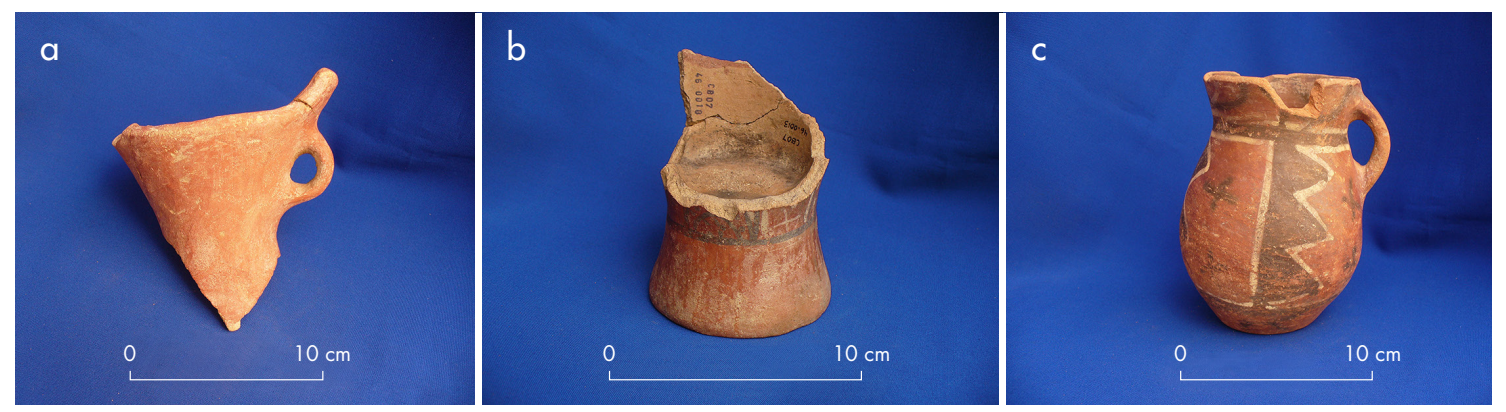

Figura 5. Fragmentos de sahumadores: a) CB07-46-0012; b) CB07-46-0013; c) jarra (CB07-46-0015), provenientes del cementerio C46. Figure 5. Shards of censers: a) CB07-46-0012; b) CB07-46-0013; c) vessel (CB07-46-0015), coming from cemetery C46.

La muestra relativa a los tazones está constituida por seis piezas (fig. 4). Cinco tazones fueron encontrados en contextos fúnebres (cementerios C45, C46 y C47), mientras que el sexto proviene de contextos domésticos.

En la figura 5 se muestran los dos fragmentos de sahumadores y una jarra que provienen del mismo sitio (cementerio C46). Estos fragmentos cerámicos fueron usados para contrastar las evidencias de marcas halladas en tazones y queros Tumilaca.

\section{MÉTODOS}

El análisis de la manufactura, la decoración y el uso de los artefactos estudiados se hizo mediante la evaluación de la cadena operativa alfarera (siguiendo a Roux 2016), organizada con nociones de métodos (sets ordenados de operaciones funcionales), que constan de fases, estados y operaciones, además de nociones de técnicas, que se componen de métodos físicos y mecánicos con los que 
se da forma a las materias primas. Así, el primer eslabón de la cadena operativa es la recolección y preparación de las materias primas para convertirlas en pasta cerámica y el segundo corresponde a los métodos y las técnicas del moldeado, en el cual el artefacto arcilloso ya tiene las características geométricas del modelo final, pero no ha recibido aún el tratamiento de superficie. El terminado (alisado) que da el acabado geométrico fino de la pieza es el siguiente eslabón para evaluar, siguiéndole el tratamiento de superficie (pulido, bruñido, etc.). La decoración es el cuarto eslabón que se evalúa, con énfasis en cierto tipo de iconografía (caracterizada de acuerdo con Panofsky 2004), dando paso a otro eslabón que es la cocción y que cierra el análisis de la manufactura del artefacto. El uso de la pieza cerámica es el último ítem de análisis.

\section{RESULTADOS}

\section{Manufactura}

La pasta usada en la cadena operativa alfarera es fina, compacta y no granulosa, con inclusiones blancas más bien pequeñas de mediana ocurrencia. El color de la arcilla cocida indica que la consolidación del material arcilloso fue mayormente oxidante, con algunas láminas y áreas negras en los núcleos que indican posibles cambios de atmósfera redox en el proceso de quema.

Con respecto al modelado del cuerpo en el tazón y el quero, este se llevó a cabo mediante el ensamblaje de anillos concéntricos de altura y grosor variables. Este tipo de marcas es más visible en la superficie interna del segmento medio inferior del cuerpo del quero; probablemente debido a que dicha área tiene un mayor trabajo de modelado estructural por ensamblaje de anillos de baja escala vertical y un menor trabajo de acabado. En general, la técnica de ensamblaje con anillos de baja escala vertical aparece en el segmento medio inferior del quero, asociado probablemente al canon de morfología hiperboloide que debe cumplir esta parte del artefacto. Por otro lado, el segmento medio superior del cuerpo del quero presenta un trabajo diferenciado que incluye generalmente dos anillos de mayor escala vertical y con menor grosor para ganar altura más rápidamente. Estos anillos se unen con buenas técnicas de presión, que incluyen los dedos; a su vez, el tratamiento de superficie es prolijo, dejando pocas evidencias del ensamblaje estructural o alisado. Estas dos preformas (área hiperboloide y área de evertido) se unen mediante una banda media (o central) que presentan algunos queros, la cual se manufactura a partir de un anillo de gran escala vertical, desplazado hacia el exterior respecto del eje mayor que lleva el cuerpo del quero. Este desplazamiento siempre tiene un mayor diámetro concéntrico para generar la banda sobresaliente característica, técnica presente también en los tazones.

Por su parte, el modelado del labio debió realizarse con los dedos pulgar e índice juntos como superficie de contacto, generando un perfil cónico de ángulo redondeado con eje concéntrico variable. En algunos casos también se pudo inferir el uso de la uña del alfarero o una superficie dura, lo que permitió dar un carácter totalmente plano a uno de los lados del cono terminal del labio.

Finalmente, la base se hizo a partir de un cuerpo arcilloso globular aplastado y cuya curvatura periférica se trabajó para adaptarla a la circunferencia del cuerpo del quero. Estas marcas fueron consistentes con la respectiva evidencia hallada en los tazones, siendo la manufactura del tazón semejante a la acción de ensamblar el área de evertido del quero con una base.

El trabajo de alisado es consistentemente más visible en los queros -sobre todo en la superficie interna del vaso- en la mitad inferior o área hiperboloide. Allí, como en los anillos estructurales, el trabajo de alisado deja marcas distintas de aquellas visibles en el área de evertido. Al respecto, la técnica de alisado considera el uso de una superficie de contacto característica de un textil, probablemente enrollado sobre sí mismo o, como en otras ocasiones, en torno a un apéndice de largo variable que permite trazos inusuales para la posibilidad de movimiento de la muñeca del alfarero. Así, por un lado, están las marcas más numerosas del borde interior de la mitad inferior del cuerpo del quero, cuyo trazo es homogéneo, regular, continuo y concéntrico, con un tipo de marca más característica de una herramienta textil con apéndice (fig. 6a). Por otro lado, la parte media superior del cuerpo del quero, que ha sido ensamblado con anillos/placas de alta escala vertical, presenta escasos vestigios del trabajo de alisado con textil en su superficie interna (fig. 6b). Allí, los trazos son heterogéneos, irregulares, discontinuos y sin ejes de orientación sistemáticamente concéntricos, lo cual es más característico de una herramienta textil manejada directamente con la mano. Este tratamiento 


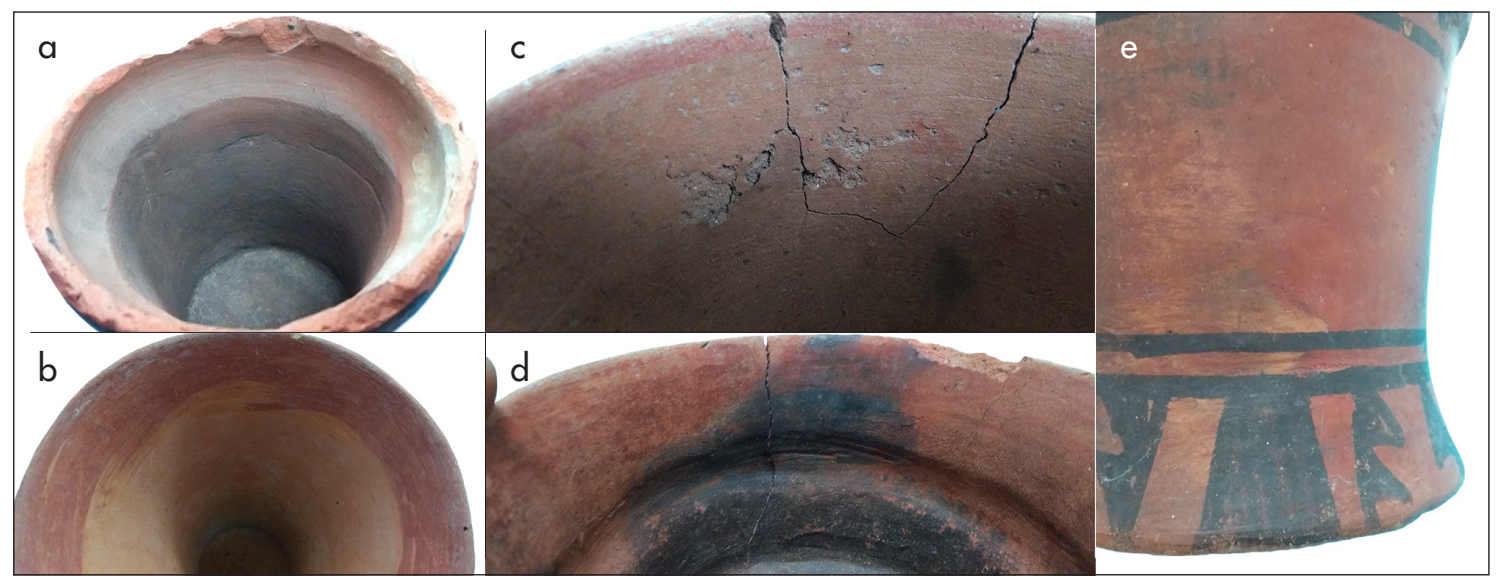

Figura 6. Detalles de: a) banda media y alisado con textil (quero CB07-45-0006); b) labio y engobe (quero CB06-47-0025); c) labio y engobe (tazón CB12-52-0103); d) banda media (tazón CB07-46-0019); e) área hiperboloide y engobe (quero CB07-46-0018). Figure 6. Details of: $\boldsymbol{a}$ ) middle band and smoothing with textile (quero CB07-45-0006); $\boldsymbol{b}$ ) edge and slip (quero CB06-47-0025); $\boldsymbol{c}$ ) edge and slip (cup CB12-52-0103); d) middle band (bowl CB07-46-0019); e) hyperboloid area and slip (quero CB07-46-0018).

de superficie diferenciado entre el área hiperboloide del quero y el área de evertido se repite en el trabajo de pulido. Por una parte, en las áreas hiperboloides del quero, en la mitad inferior del cuerpo, las marcas de pulido son verticales $\mathrm{y} / \mathrm{u}$ oblicuas, $\mathrm{y}$, por otra, las marcas de pulido son horizontales en la mitad superior del cuerpo del quero (área de evertido) y en la banda media. Estas marcas en la superficie interna del quero no son tan visibles en los tazones, siendo reemplazadas por otro tipo de marcas.

\section{Decoración}

La totalidad de las piezas analizadas presenta un engobe rojo que se distribuye por la superficie del cuerpo, exceptuando la base de los objetos; mientras que en la superficie interna de queros y tazones el engobe se encuentra solo en las áreas del labio (figs. 6b, c y d y 7). Las marcas indicarían que el engobe fue aplicado con brochas de aproximadamente $0,5 \mathrm{a} 1 \mathrm{~cm}$, con un acabado de heterogénea calidad, con áreas de menor densidad de pintado y/o preparados aguados del engobe (fig. 6e). Sobre este engobe en rojo se hizo el trazado en negro con un pincel de $0,2-0,3 \mathrm{~cm}$ aproximadamente, usado también en el caso de que el color negro fuese utilizado para el relleno de bandas de ancho mayor (figs. 6e y 7a y b). Cuando aparece el color blanco es para trazado y se aplica sobre el negro (fig. 7a y c), en cambio, el color anaranjado sirve para relleno de áreas (fig. 7a). Cuando se trata de una línea que rodea el quero (haciendo un círculo), se hace generalmente en secciones, dejando pequeñas aristas en el delineado que denotan las veces que el alfarero retomó dicho trazado (fig. 7 a y c).

Por su parte, la representación iconográfica se despliega en el quero en cinco áreas diferentes: a) panel superior, correspondiente al área de evertido; b) banda media (dibujada o modelada); c) panel inferior, correspondiente al área hiperboloide; d) panel del extremo inferior (área de la base); e) área interior del borde superior (área del labio).

El tazón muestra decoración en todo el cuerpo, como un solo panel, en analogía con las áreas evertidas del quero, salvo quizás en el caso del tazón CB07-46-0019, con banda media (figs. 6d y 7d). La iconografía propiamente tal se puede agrupar en tres conjuntos decorativos: 1) motivos figurativos donde aparece generalmente un tipo de flamenco, además de representaciones modeladas de "lagartos", 2) diseños geométricos y escalerados, que aparecen preferentemente en los queros, y 3) diseños ondulados o volutas, delimitados por líneas o bandas formando espacios cerrados, preferentemente en los tazones. El nivel preiconográfico de este último tipo de decoración-denominada "estética ondulada"- se compone de trazos ondulados, líneas, barras rellenas de grosor variable, líneas punteadas, semicírculos, semicírculos punteados, puntos, triángulos rellenos y excepcionalmente escalerados. Luego, en el nivel iconográfico, estos 


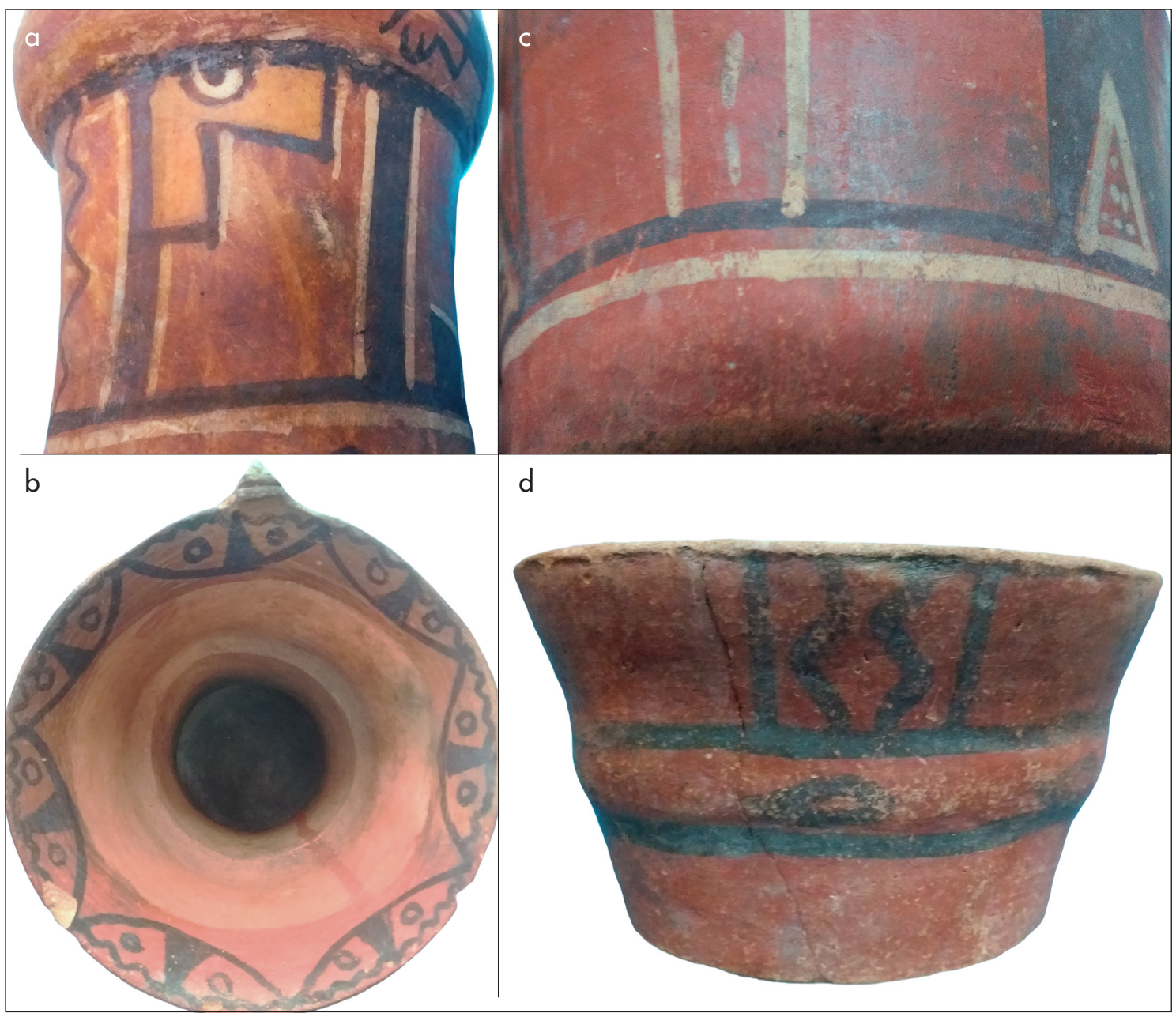

Figura 7. Detalles de: a) paleta de colores del estilo Tumilaca (quero CB07-45-0006); b) decoración en labio interno (quero CB07-460018); c) trazo blanco sobre negro (tazón CB12-52-0103); d) estética ondulada (tazón CB07-46-0019). Figure 7. Details of: a) Tumilaca style color palette (quero CB07-45-0006); b) decoration on inner edge (quero CB07-46-0018); c) white stroke on black (bowl CB12-52-0103); d) wavy lines (bowl CB07-46-0019).

íconos se plasman de forma unitaria, doble o triple (p. e., líneas onduladas), además de conformaciones con dos o más unidades icónicas distintas (p. e., líneas onduladas entre dos rectas, barra y línea ondulada, etc.) o conformaciones más complejas de varias unidades. En términos iconográficos, algunos de estos íconos o sus combinaciones se despliegan como patrones secuenciales en torno al perímetro de la forma (figs. 4 y $7 \mathrm{~d}$ ).

\section{Contextos de uso}

Evidentemente, el uso fúnebre de estos artefactos es el metaparadigma que define y aúna en el rito mortuorio a queros y tazones y, por ello, exceptuando dos casos, la totalidad de los objetos analizados comparten este primer plano semántico de uso. Esto es importante, pues una comparación de la superficie en la base de los queros estudiados muestra que estos artefactos aún mantienen una superficie texturada, con marcas de textil, pintura o marcas subjetivas (fig. $8 \mathrm{a}, \mathrm{b}$ y c). Esto es muy distinto de la base del quero hallado en contextos rituales, el cual presenta una superficie homogeneizada y desgastada por fricción (fig. 8d). Es la misma superficie desgastada en la base de los tazones de contextos fúnebres (figs. 6d, 8e, f y g) y del tazón hallado en contextos domésticos (figs. 6c y 8h). 


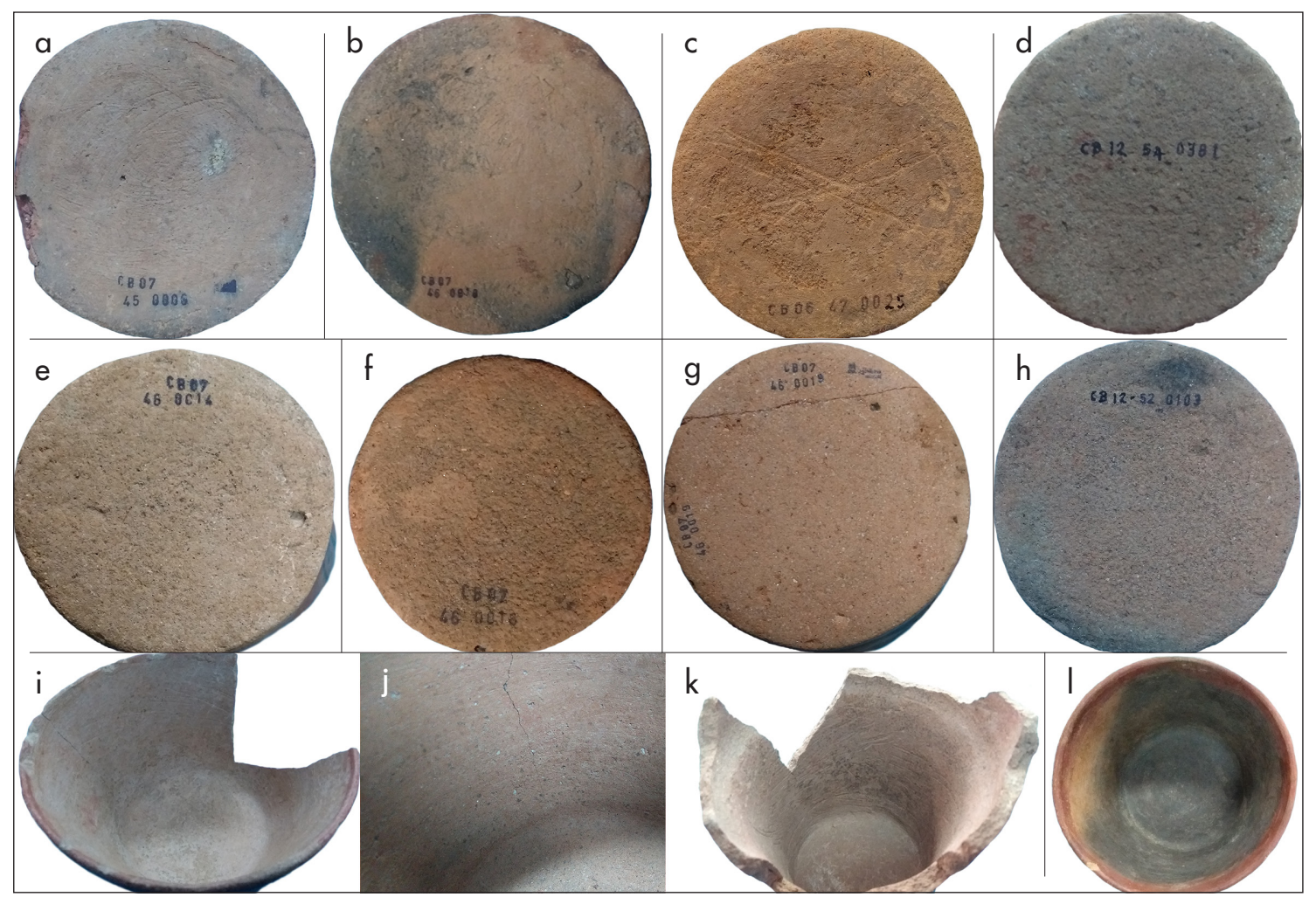

Figura 8. Detalles de la base de queros: a) CB07-45-0006; b) CB07-46-0018; c) CB06-47-0025; d) CB12-54-0381. Detalles de la base de tazones: e) CB07-46-0014, f) CB07-46-0016; g) CB07-46-0019; h) CB12-52-0103. Detalles de la superficie interna de tazones: i) CB0746-0014; j) CB12-52-0103; de la superficie interna de queros: k) CB12-54-0381; 1) de un evento de quema en un tazón: CB06-47-0027. Figure 8. Details of the base of queros: a) CB07-45-0006; b) CB07-46-0018; c) CB06-47-0025; d) CB12-54-0381. Details of the base of bowls: e) CB07-46-0014, f) CB07-46-0016; g) CB07-46-0019; h) CB12-52-0103. Details of the inner surfaces of bowls: i) CB07-46-0014; j) CB12-52-0103; of the inner surfaces of queros: $k$ ) CB12-54-0381; l) of a burning event in a bowl: CB06-47-0027.

De manera análoga, la superficie interna de los queros revela aún profusos detalles del trabajo de manufactura (fig. 6a) y superficies pulcras sin cambios de color por contenido (figs. $6 \mathrm{~b}$ y $7 \mathrm{~b}$ ) que sugieren poco uso, a diferencia de los tazones que tienen una superficie interna homogénea con rastros de fricción mecánica de desgaste por raspaje punzante, que borra totalmente el trabajo de alisado o pulido (fig. 8i). Este tipo de superficie gastada mecánicamente es muy semejante a la que exhibe el tazón hallado en contextos domésticos (fig. $8 j$ ) y al quero encontrado en contextos rituales, el cual consigna, además, cambios de color característicos de la presencia de materia orgánica (áreas oscuras en fig. 8k). De igual forma, los labios de queros (figs. $6 \mathrm{~b}$ y $7 \mathrm{~b}$ ) están bastante conservados; en los tazones, por el contrario, es notorio cierto desgaste (figs. $7 \mathrm{c} \mathrm{y} \mathrm{d} \mathrm{y} 8 \mathrm{i}$ ). Esto hace suponer que los tazones y el quero de contextos rituales fueron profusamente usados, en tanto que los queros de contextos fúnebres no contienen señales de uso sistemático. Principalmente en los queros funerarios estudiados no hay evidencia de cambio de color o depósito sistemático de materia orgánica, tampoco se observan labios o bases gastadas o superficies internas erosionadas con señales que sugieran raspados de limpieza, conservando muchas de las marcas de su manufactura. Finalmente, se presentan casos de quema en queros (fig. 7b) y tazones (figs. 6d y 8l), los cuales parecen corresponder a eventos pirolíticos realizados en ritos de último momento.

\section{DISCUSIÓN}

En términos generales, las arcillas finas con inclusiones de tamaño pequeño y buena distribución permiten suponer que los alfareros de estas piezas tenían un 
buen manejo de los materiales -y de los paisajes donde encontrarlos- para producir las piezas estudiadas. Así, técnicas como el ensamblaje de la preforma con anillos, la banda media con anillo desplazado, el alisado con textil, el modelado del labio, la concepción del área de evertido, etcétera, son elementos técnicos comunes en los artefactos Tumilaca analizados. Por ello, la coherencia técnica y el acabado de los queros y tazones, en conjunto con las otras piezas estudiadas (fig. 4), dan a entender que estos artefactos son producto de una tradición alfarera cohesionada en tiempos posestatales. Sin embargo, esta tradición posestatal es la que mejor emuló formas canónicas clásicas del Estado Tiwanaku como el quero, icónico también en la colonia estatal del área de Moquegua, lo que supone una continuidad cultural con el Horizonte Medio (Sharratt 2011, 2015). Es más, la evidencia química asociada a piezas de la tradición Tumilaca permite plantear que estos alfareros podrían haber seguido utilizando algunas de las arcillas que ocuparon los alfareros Chen Chen de la colonia Tiwanaku, al tiempo que otras fuentes locales también eran exploradas en La Chimba (Sharratt et al. 2015), lo que implicaría paisajes compartidos. Claramente, cierta parte de la producción cerámica Tumilaca podría ser un puente material de continuidad cultural factual o simbólica entre los momentos estatales y la propia realidad posestatal del grupo.

Otro puente de continuidad cultural con el Horizonte Medio es la decoración cromática del estilo Tumilaca, compuesta de los colores rojo, negro, blanco y anaranjado. Luego - y tal como ocurre en piezas altiplánicas de estilo Tiwanaku ya estudiadas (Ogalde et al. 2020)-, es muy probable que los colores rojo y negro se elaborasen a base de hierro y manganeso, respectivamente, y se aplicaran antes del eslabón de cocción, pues resisten altas temperaturas (aprox. $900{ }^{\circ} \mathrm{C}$ ). En el caso del color anaranjado y el blanco (figs. 7a y c, 9a y b), pudieron necesitar procesos de poscocción cuando aparece incorporado el yeso. Esto puesto que el yeso tiene moléculas de agua químicamente enlazadas que se evaporan totalmente a los $400{ }^{\circ} \mathrm{C}$, de modo que si hay presencia de yeso en la composición de los colores blanco o anaranjado significa que no se sobrepasó dicha temperatura. Por lo tanto, la fijación térmica de este compuesto como blanco o como anaranjado requirió seguramente procesos de poscocción. Esto explica por qué el blanco va sobre el negro (figs. 7c y 9b). Entonces, el proceso de decoración pudo necesitar procesos tér- micos intercalados para la producción del color, lo que remarca el hecho de que los artesanos contaban con un esquema mental previo (prototipo) para la producción ordenada del color y la decoración iconográfica de las cerámicas estudiadas, esquema que se desplegaba en el tiempo y que podía incluir secuencias térmicas de rango variable.

Parte de estos esquemas mentales pictóricos usados en la decoración conllevarían niveles iconográficos compartidos con otras tradiciones alfareras estatales y posestatales, en especial la denominada estética ondulada. Al respecto, en las áreas nucleares del Estado Tiwanaku se ha caracterizado el estilo Chambi como una cerámica con un amplio despliegue espacial circumtiticaca y un desarrollo temporal de ca. 600 a 1100 DC. Este estilo cerámico, compuesto mayormente de queros, jarras y tazones, presenta en todas sus formas la denominada estética ondulada con el flamenco como único motivo figurativo (Burkholder 2001: 233, fig. 12; 235, fig. 14). Luego, este estilo aparece en toda la secuencia cronológica y cultural de la Pirámide de Akapana (Alconini 1995: 107, fig. 26; 230, fig. 89), asociado frecuentemente al tazón y en contextos cívicos antes que rituales, más relacionados con el ámbito cotidiano y la alimentación (Alconini 1995; Burkholder 2001). La estética ondulada aparece también en el estilo caracterizado como Tiraska, otra tradición alfarera altiplánica cuyo desarrollo abarca ca. 893-1221 DC (Korpisaari 2004: 117, figs. 2 y 3; 2006 : 121, figs. 7-11; 123, figs. 7-15; 128, figs. 7-22; 138, figs. 7-40). Es interesante notar que, a pesar de la cercanía de este sitio con la isla de Pariti, donde se hicieron suntuosas ofrendas estatales de cerámicas Tiwanaku, esta población es considerada común, cívica o más modesta, respecto de las élites sociales que presidían los procesos estatales de Tiwanaku (Korpisaari 2004, 2006). Luego, tanto en las áreas periféricas del Estado Tiwanaku como en las colonias del área de Moquegua, aparece también la estética ondulada y motivos de flamencos en la alfarería Chen Chen, representada mayormente en tazones (Goldstein \& Owen 2001: 157, fig. 13). Por lo tanto, la asociación de formas cerámicas y elementos iconográficos con una función en el ámbito cívico y cotidiano de la alimentación pudieron ser las razones de difusión y permanencia de dicha decoración. En este sentido, es interesante señalar que en las excavaciones del sitio Tumilaca la Chimba se han encontrado varios tazones en lugares domésticos (Sharratt 2011, 2015), como la pieza que hemos estudiado (CB12-52-0103), en 


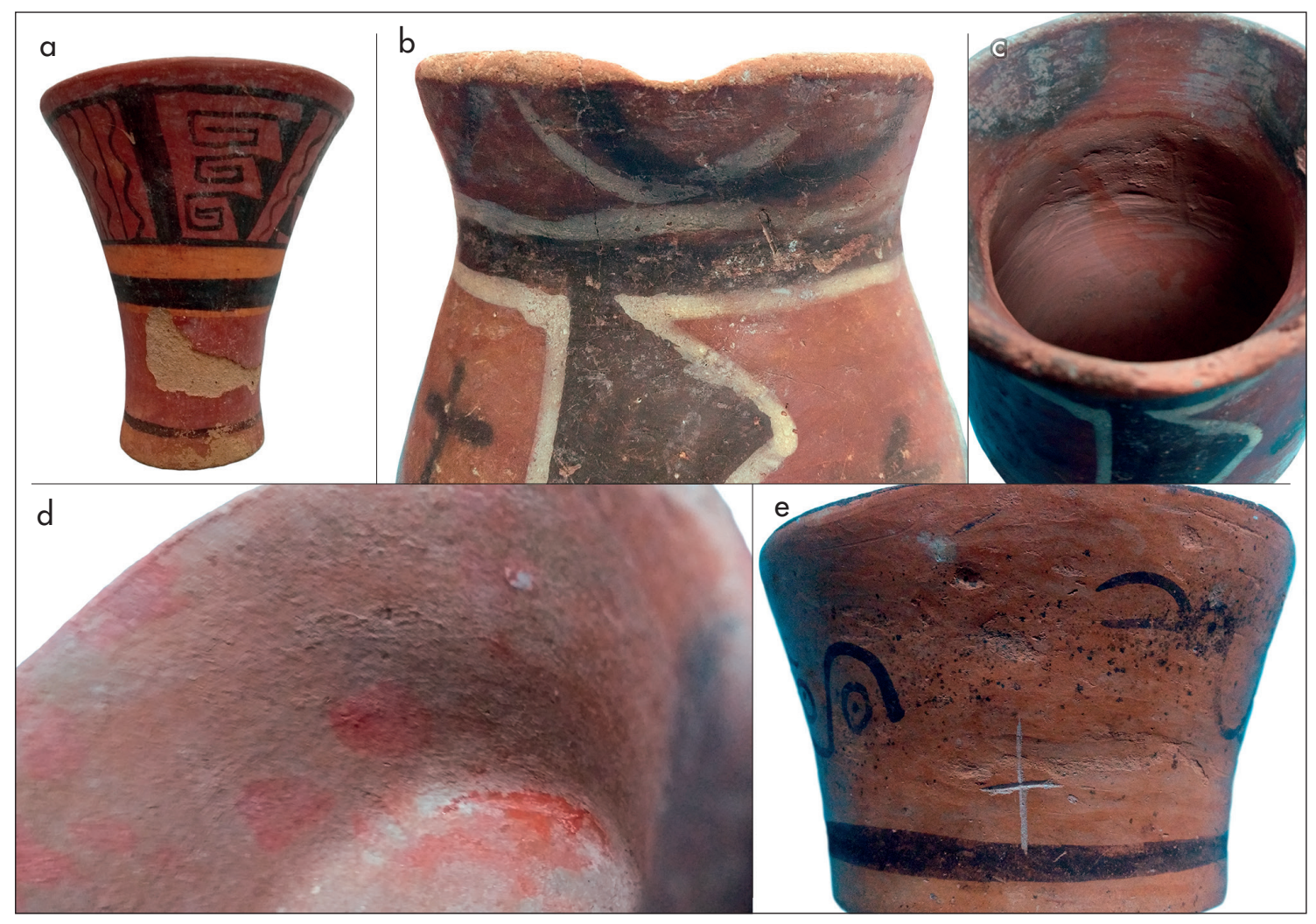

Figura 9. Detalles de: a) banda media pictórica asimétrica (quero CB06-47-0025); b) blanco sobre negro (nótese el labio gastado en la jarra CB07-46-0015); c) escurrimiento de engobe (jarra CB07-46-0015); d) marcas dactilares con pigmento rojo en sahumador (CB0746-0013); e) marcas subjetivas de incisión (tazón CB07-45-00015). Figure 9. Details of: a) asymmetric pictorial middle band (quero CB06-47-0025); $\boldsymbol{b}$ ) white on black (note worn-out edge in vessel CB07-46-0015); $c$ ) slip drip (vessel CB07-46-0015); d) fingerprints with red pigment in censer (CB07-46-0013); e) subjective incision marks (bowl CB07-45-00015).

tanto los queros se han hallado más bien en contextos rituales o fúnebres.

Esta probable función cotidiana de los tazones Tumilaca sería coherente con las marcas de uso sistemático de dicho artefacto, lo que podría remitir al ámbito cívico de la sociedad y a su vajilla doméstica. Por su parte, los queros de contextos fúnebres podrían estar estrechamente ligados al rito fúnebre, acercándose este artefacto al uso escatológico del grupo. Esta idea es reforzada por las diversas marcas que denotan una desprolijidad, premura o inexperticia en la producción y el acabado cromático del quero Tumilaca -escurrimientos de pintura, engobe desigual, deformación estructural, asimetrías, etcétera (figs. 6a, b y e, 7b y 9a)-, como si el quero fuese producido a contramarcha o por manos inexpertas, quizás en paralelo a la preparación del cuerpo y de la cista funeraria. Cabe notar que también hay algunos indicios de escurrimientos de engobe en tazones (figs. 6 c y $8 \mathrm{i}$ ), jarras (fig. 9c) y sahumadores, y la aparente recurrencia de alguna de estas marcas (huellas dactilares cromáticas en figs. 6a y 9d) hace pensar en los aspectos particulares de este tipo de evidencia. Ciertamente, algunos queros y tazones presentaron marcas de incisión (figs. 5b, 8c y 9e) que sugieren elementos subjetivos detrás de la funcionalización de estos artefactos. Toda esta evidencia arqueológica llama la atención sobre los aspectos simbólicos y subjetivos de los queros y tazones en el registro fúnebre de Tumilaca, toda vez que plantean relaciones materiales entre el mundo cotidiano y las concepciones escatológicas del grupo.

Sin duda, esta última reflexión es importante, puesto que los hallazgos del poco uso del quero funerario posestatal de Tumilaca la Chimba difiere significativamente respecto del uso de queros estudiados tipo Tiwanaku de la fase Chen Chen en Moquegua (Sharratt 2011, 2015) o de los queros Tiwanaku de áreas cercanas (valle de 
Azapa) o del altiplano (Ogalde 2015; Ogalde et al. 2020), muchos de los cuales muestran evidencias claras de una utilización sistemática en la ingesta de chichas (color, olor, erosión, etc.). Así, durante la vigencia del Estado Tiwanaku, el vaso quero es usado como ofrenda o en libaciones rituales recurrentes, aunque en momentos posestatales parte importante de su producción pareciera destinarse para ritos funerarios. En la medida en que estas prácticas (libación ritual, rito funerario, etc.) arraigan en el habitus o en las identidades prescriptivas del registro fúnebre Tumilaca (Sharratt 2010, 2011), son evidencias de un cambio cultural profundo en el uso y la concepción del quero, el cual ciertamente podría estar relacionado con el colapso del Estado Tiwanaku y el cese de sus libaciones rituales. Esta podría ser una ruptura cultural posestatal de envergadura en la fase Tumilaca con respecto al Horizonte Medio.

\section{REFLEXIONES FINALES}

Todos estos elementos podrían estar en la mente del alfarero Tumilaca cuando, por la mañana, se prepara para realizar la tarea del día (sea cual sea la fenomenología de este tipo de labor), pensando en los tazones de iconografía ancestral que se ofrendarían con la muerte de algún conocido, suceso que lo obligaría a producir un quero ex profeso. Pensamos que, en el caso del estilo Tumilaca, este tipo de escenarios más íntimos y culturales son los que dieron continuidad y, más importante aún, desecharon ciertos elementos iconográficos o de formas alfareras que estuvieron presentes en la multiculturalidad del Estado Tiwanaku. Esta selección de ítems (morfotipos, iconografía, etc.) en virtud de la multiculturalidad interna de la colapsada colonia del área de Moquegua, permitió reconstruir rápidamente la identidad cultural del grupo posestatal en los nuevos espacios conseguidos. Sin embargo, elementos de gran significado cultural como el uso y la concepción del quero al parecer presentaron cambios o rupturas culturales importantes, pudiendo pasar de un contexto estatal de libación ritual sistemática al ámbito escatológico del grupo que no lo usa para beber. Es una trágica y nostálgica constancia de que las libaciones rituales se resignificaron en parte debido a que el Estado ya no estaba presente, marcando así un devenir contingente con los tiempos posestatales. Estudios de amplio espectro espacial y temporal en esta área y los enclaves mencionados podrían detallar estas primeras impresiones exploratorias en Tumilaca la Chimba.

Reconocimientos Las excavaciones en La Chimba entre 2007 y 2012 fueron financiadas por National Science Foundation, EE.UU. (DDIG 0937303), National Geographic Society (9096-12), Fulbright IIE, Dumbarton Oaks y Curtiss T. \& Mary G. Brennan Foundation. También, se agradece al Departamento de Antropología y Graduate College de la University of Illinois Chicago, además del Women's Board y el Departamento de Antropología del Field Museum en Chicago. Las excavaciones en Tumilaca la Chimba entre 2007 y 2012 fueron realizadas bajo el permiso del Ministerio de Cultura del Perú, Lima (RDN 1208/INC), a nombre de P. R. Williams y M. E. Rojas Chávez en 2006-2007; RDN 1350/INC a nombre de P. R. Williams y M. Lizárraga Ibáñez en 2010; RDN 301-2012 a nombre de D. Nash y S. Chacaltana Cortez en 2012. Análisis del material cerámico hecho en 2017 bajo el permiso del Ministerio de Cultura del Perú, Lima (RDN 025-2017- DMG-VMPCIC/MC, a nombre de S. Chacaltana Cortez). Agradecimientos al Museo Contisuyo.

\section{REFERENCIAS}

Albarracín-Jordán, J. 1997. Prehispanic and early Colonial settlement patterns in the lower Tiwanaku valley, Bolivia. Tesis para optar al grado de Doctor en Antropología, Faculty of Dedman College, Southern Methodist University, Dallas. <https://ehrafarchaeology.yale.edu/document?id=sf50-001> [consultado: 10-11-2021].

Albarracín-Jordan, J. \& J. E. Mathews 1990. Asentamientos prehispánicos del valle de Tiwanaku. Volumen I. La Paz: cima.

Alconini, S. 1995. Rito, símbolo e historia en la pirámide de Akapana, Tiwanaku: un análisis de cerámica ceremonial prehispánica. La Paz: Acción.

Bawden, G. 1989. The Tumilaca site and post-Tiahuanaco occupational stratigraphy in the Moquegua drainage. En Ecology, settlement and history in the Osmore drainage, Peru, D. S. Rice, C. Stanish \& P. R. Scarr, eds., vol. II, pp. 287-302. Oxford: BAR International Series.

BAWDEN, G. 1993. An archaeological study of social structure and ethnic replacement in residential architecture of the Tumilaca valley. En Domestic architecture, ethnicity, and complementarity in the south-central Andes, M. S. Aldenderfer, ed., pp. 42-54. Iowa City: University of Iowa Press.

Bennett, W. C. 1934. Excavations at Tiahuanaco. Anthropological Papers 34 (3). Nueva York: American Museum of Natural History. <http://hdl.handle.net/2246/79> [consultado: 15-08-2021]. 
Bennett, W. C. 1936. Excavations in Bolivia. Anthropological Papers 35 (4). Nueva York: American Museum of Natural History. <http://hdl.handle.net/2246/120> [consultado: 15-08-2021].

Bermann, M. 1990. Prehispanic household and empire at Lukurmata, Bolivia. Tesis para optar al grado de Doctor en Antropología, University of Michigan, Ann Arbor.

Bermann, M., P. S. Goldstein, C. Stanish \& L. Watanabe 1989. The collapse of the Tiwanaku state: a view from the Osmore drainage. En Ecology, settlement and history in the Osmore drainage, Peru, D. S. Rice, C. Stanish \& P. R. Scarr, eds., vol. II, pp. 269-285. Oxford: BAR International Series.

BuRKHOLDER, J. E. 2001. La cerámica de Tiwanaku: ¿qué indica su variabilidad? Boletín de Arqueología PUCP 5: 217-249.

Cook, A. G. 1994. Wari y Tiwanaku: entre el estilo y la imagen. Lima: Fondo Editorial de la Pontificia Universidad Católica del Perú.

Goldstein, P. S. 2005. Andean diaspora: the Tiwanaku colonies and the origins of South American empire. Gainesville: University Press of Florida.

Goldstein, P. S. \& B. D. Owen 2001. Tiwanaku en Moquegua: las colonias altiplánicas. Boletín de Arqueología PUCP 5: 139-168.

JANUSEK, J. W. 2002. Out of many, one: style and social boundaries in Tiwanaku. Latin American Antiquity 13 (1): 35-61.

JANUSEK, J. W. 2003. Vessels, time, and society: toward a ceramic chronology in the Tiwanaku heartland. En Tiwanaku and its hinterland: archaeology and paleoecology of an Andean civilization. Volume 2: Urban and rural archaeology, A. L. Kolata, ed., pp. 30-91. Washington DC: Smithsonian Institution Press.

KorPISAArI, A. 2004. Entierros y jerarquía social Tiwanaku. El caso del cementerio de Tiraska. En Tiwanaku: aproximaciones a sus contextos históricos y sociales, M. Rivera \& A. L. Kolata, eds., pp. 99-126. Santiago: Universidad Bolivariana.

KorPISAARI, A. 2006. Death in the Bolivian high plateau: burials and Tiwanaku society. Oxford: BAR International Series.

KorpisaAri, A. \& J. Chacama (comps.) 2015. El Horizonte Medio: nuevos aportes para el sur del Perú, norte de Chile y Bolivia. Lima-Arica: Instituto Francés de Estudios Andinos-Universidad de Tarapacá.

Lowman, S. A., N. Sharratt \& B. L. Turner 2019. Bioarchaeology of social transition: a diachronic study of health at Tumilaca la Chimba, Peru. International Journal of Osteoarchaeology 29 (1): 62-72.

Mathews, J. E. 1992. Prehispanic settlement and agriculture in the middle Tiwanaku Valley, Bolivia. Tesis para optar al grado de Doctor en Antropología, University of Chicago.

Ogalde, J. P., A. Korpisaari, C. Riera-Soto, B. Arriaza, C. Paipa, P. Leyton, M. Campos-Vallette, N. Lara \& J. Chacama 2020. Archaeometric analysis of ceramic production in the Tiwanaku state (ca. 500-1000 CE): an exploratory study. Archaeometry 63 (1): 53-67. <https:// doi.org/10.1111/arcm.12597> [consultado: 15-08-2021].
Owen, B. D. 2005. Distant colonies and explosive collapse: the two stages of the Tiwanaku diaspora in the Osmore drainage. Latin American Antiquity 16: 45-80.

Owen, B. D. \& P. S. Goldstern 2001. Tiwanaku en Moquegua: interacciones regionales y colapso. Boletín de Arqueología PUCP 5: 169-188.

PANOFSKy, E. 2004. Estudios sobre iconología. Madrid: Alianza.

Parker, B. J. \& N. Sharratt 2017. Fragments of the past: applying microarchaeological techniques to use surfaces at Tumilaca la Chimba, Moquegua, Peru. Advances in Archaeological Practice 5: 71-92.

Ponce SAnginés, C. 1981. Tiwanaku: espacio, tiempo y cultura. Ensayo de síntesis arqueológica. La Paz-Cochabamba: Los Amigos del Libro.

Roux, V. 2016. Ceramic manufacture: the chaine opératoire approach. En Archaeology, archaeological methodology and techniques. Production, trade, and exchange, A. Hunt, ed., pp. 1-17. <10.1093/oxfordhb/9780199681532.013.8> [consultado: 15-08-2021].

Rydén, S. 1947. Archaeological researches in the highlands of Bolivia. Gotemburgo: Elanders Boktryckeri.

ShARRATT, N. 2010. Identity negotiation during Tiwanaku state collapse. En Identity crisis. Archaeological perspectives on social identity, L. Amundsen-Meyer, N. Engel \& S. Pickering, comps., pp. 167-177. Calgary: Chacmool Archaeological Association.

Sharratt, N. 2011. Social identities and state collapse: a diachronic study of Tiwanaku burials in the Moquegua valley, Peru. Tesis para optar al grado de Doctor en Antropología, Departamento de Antropología, University of Illinois, Chicago.

Sharratt, N. 2015. Viviendo y muriendo en medio de la efervescencia política: excavaciones en una aldea Tiwanaku Terminal (950-1150 DC) del valle de Moquegua, Perú. En El Horizonte Medio: nuevos aportes para el sur del Perú, norte de Chile y Bolivia, A. Korpisaari \& J. Chacama, comps., pp. 201-223. Lima-Arica: Instituto Francés de Estudios Andinos-Universidad de Tarapacá.

Sharratt, N. 2016a. Crafting a response to collapse: ceramic and textile production in the wake of Tiwanaku state breakdown. En Beyond collapse. Archaeological perspectives on resilience, revitalization, and transformation in complex societies, R. K. Faulseit, comp., pp. 407-430. Carbondale, IL: SIU Press.

Sharratt, N. 2016b. Collapse and cohesion: building community in the aftermath of Tiwanaku state breakdown. World Archaeology 48 (1): 144-163.

SharratT, N. 2017. Steering clear of the dead: avoiding ancestors in the Moquegua valley, Peru. American Anthropologist 119: 645-661.

Sharratt, N. 2019. Tiwanaku's legacy: a chronological reassessment of the terminal Middle Horizon in the Moquegua valley, Peru. Latin American Antiquity 30 (3): 529-549. 
ShARRATT, N. 2020. Rejecting, reinventing, resituating: a diachronic perspective on ritual in the aftermath of Tiwanaku state collapse. En Rituals, collapse, and radical transformation in archaic states, J. Murphy, ed., pp. 123146. Nueva York: Routledge.

Sharratt, N., P. R. Williams, M. C. Lozada Cerna \& J. STARBIRD 2012. Late Tiwanaku mortuary patterns in the Moquegua drainage, Peru: excavations at the Tumilaca la Chimba cemetery. En Advances in Titicaca basin archaeology III, A. Vranich, E. Klarich \& C. Stanish, eds., pp. 193-203. Ann Arbor: Museum of Anthropology Publications.

Sharratt, N., M. Golitko \& P. R. Williams 2015. Pottery production, regional exchange and state collapse during the Middle Horizon (AD 500-1000): LA-ICP-MS analyses of Tiwanaku pottery in the Moquegua valley, Peru. Journal of Field Archaeology 40 (4): 397-412.

Sutter, R. C. \& N. Sharratt 2010. Continuity and transformation during the Terminal Middle Horizon (AD
950-1150): a bioarchaeological assessment of Tumilaca origins within the middle Moquegua valley, Peru. Latin American Antiquity 21: 67-86.

Uribe, M. 1999. La cerámica de Arica 40 años después de Dauelsberg. Chungara 31 (2): 189-228.

Wallace, D. T. 1957. The Tiahuanaco horizon styles in the Peruvian and Bolivian highlands. Tesis para optar al grado de Doctor en Antropología, Departamento de Antropología, University of California, Berkeley.

Williams, P. R. 2008. Informe de campo e informe final. Proyecto arqueológico Cerro Baúl 2006-2007. <https:// www.fieldmuseum.org/sites/default/files/CB06inf.pdf> [consultado: 15-08-2021].

Williams, P. R., M. LizÁrraga \& N. Sharratt 2010. Informe de campo e informe final. Proyecto arqueológico Cerro Baúl 2010. <https://www.fieldmuseum.org/sites/default/ files/cb10inf.pdf> [consultado: 15-08-2021]. 